\title{
The multiplicative Zagreb indices of graph operations
}

\author{
Kinkar C Das ${ }^{1}$, Aysun Yurttas², Muge Togan², Ahmet Sinan Cevik ${ }^{3}$ and Ismail Naci Cangul2*
}

"Correspondence:

cangul@uludag.edu.tr

${ }^{2}$ Department of Mathematics,

Faculty of Arts and Science, Uludağ

University, Gorukle Campus, Bursa,

16059, Turkey

Full list of author information is

available at the end of the article

\section{Abstract}

Recently, Todeschini et al. (Novel Molecular Structure Descriptors - Theory and Applications I, pp. 73-100, 2010), Todeschini and Consonni (MATCH Commun. Math. Comput. Chem. 64:359-372, 2010) have proposed the multiplicative variants of ordinary Zagreb indices, which are defined as follows:

$$
\prod_{1}=\prod_{1}(G)=\prod_{v \in V(G)} d_{G}(v)^{2}, \quad \prod_{2}=\prod_{2}(G)=\prod_{u v \in E(G)} d_{G}(u) d_{G}(v) .
$$

These two graph invariants are called multiplicative Zagreb indices by Gutman (Bull. Soc. Math. Banja Luka 18:17-23, 2011). In this paper the upper bounds on the multiplicative Zagreb indices of the join, Cartesian product, corona product, composition and disjunction of graphs are derived and the indices are evaluated for some well-known graphs.

MSC: 05C05; 05C90; 05C07

Keywords: graph; multiplicative Zagreb index; graph operations

\section{Introduction}

Throughout this paper, we consider simple graphs which are finite, indirected graphs without loops and multiple edges. Suppose $G$ is a graph with a vertex set $V(G)$ and an edge set $E(G)$. For a graph $G$, the degree of a vertex $v$ is the number of edges incident to $v$ and is denoted by $d_{G}(v)$. A topological index $\operatorname{Top}(G)$ of a graph $G$ is a number with the property that for every graph $H$ isomorphic to $G$, $\operatorname{Top}(H)=\operatorname{Top}(G)$. Recently, Todeschini et al. [1,2] have proposed the multiplicative variants of ordinary Zagreb indices, which are defined as follows:

$$
\prod_{1}=\prod_{1}(G)=\prod_{v \in V(G)} d_{G}(v)^{2}, \quad \prod_{2}=\prod_{2}(G)=\prod_{u v \in E(G)} d_{G}(u) d_{G}(v) .
$$

Mathematical properties and applications of multiplicative Zagreb indices are reported in [1-6]. Mathematical properties and applications of multiplicative sum Zagreb indices are reported in [7]. For other undefined notations and terminology from graph theory, the readers are referred to [8].

In $[9,10]$, Khalifeh et al. computed some exact formulae for the hyper-Wiener index and Zagreb indices of the join, Cartesian product, composition, disjunction and symmetric

\section{空 Springer}

(c) 2013 Das et al.; licensee Springer. This is an Open Access article distributed under the terms of the Creative Commons Attribution License (http://creativecommons.org/licenses/by/2.0), which permits unrestricted use, distribution, and reproduction in any medium, provided the original work is properly cited. 
difference of graphs. Some more properties and applications of graph products can be seen in the classical book [11].

In this paper, we give some upper bounds for the multiplicative Zagreb index of various graph operations such as join, corona product, Cartesian product, composition, disjunction, etc. Moreover, computations are done for some well-known graphs.

\section{Multiplicative Zagreb index of graph operations}

We begin this section with two standard inequalities as follows.

Lemma 1 (AM-GM inequality) Let $x_{1}, x_{2}, \ldots, x_{n}$ be nonnegative numbers. Then

$$
\frac{x_{1}+x_{2}+\cdots+x_{n}}{n} \geq \sqrt[n]{x_{1} x_{2} \cdots x_{n}}
$$

holds with equality if and only if all the $x_{k}$ 's are equal.

Lemma 2 (Weighted AM-GM inequality) Let $x_{1}, x_{2}, \ldots, x_{n}$ be nonnegative numbers and also let $w_{1}, w_{2}, \ldots, w_{n}$ be nonnegative weights. Set $w=w_{1}+w_{2}+\cdots+w_{n}$. If $w>0$, then the inequality

$$
\frac{w_{1} x_{1}+w_{2} x_{2}+\cdots+w_{n} x_{n}}{w} \geq \sqrt[w]{x_{1}^{w_{1}} x_{2}^{w_{2}} \cdots x_{n}^{w_{n}}}
$$

holds with equality if and only if all the $x_{k}$ with $w_{k}>0$ are equal.

Let $G_{1}$ and $G_{2}$ be two graphs with $n_{1}$ and $n_{2}$ vertices and $m_{1}$ and $m_{2}$ edges, respectively. The join $G_{1} \vee G_{2}$ of graphs $G_{1}$ and $G_{2}$ with disjoint vertex sets $V\left(G_{1}\right)$ and $V\left(G_{2}\right)$ and edge sets $E\left(G_{1}\right)$ and $E\left(G_{2}\right)$ is the graph union $G_{1} \cup G_{2}$ together with all the edges joining $V\left(G_{1}\right)$ and $V\left(G_{2}\right)$. Thus, for example, $\bar{K}_{p} \vee \bar{K}_{q}=K_{p, q}$, the complete bipartite graph. We have $\left|V\left(G_{1} \vee G_{2}\right)\right|=n_{1}+n_{2}$ and $\left|E\left(G_{1} \vee G_{2}\right)\right|=m_{1}+m_{2}+n_{1} n_{2}$

Theorem 1 Let $G_{1}$ and $G_{2}$ be two graphs. Then

$$
\prod_{1}\left(G_{1} \vee G_{2}\right) \leq\left[\frac{M_{1}\left(G_{1}\right)+4 m_{1} n_{2}+n_{1} n_{2}^{2}}{n_{1}}\right]^{n_{1}} \times\left[\frac{M_{1}\left(G_{2}\right)+4 n_{1} m_{2}+n_{2} n_{1}^{2}}{n_{2}}\right]^{n_{2}}
$$

and

$$
\begin{aligned}
\prod_{2}\left(G_{1} \vee G_{2}\right) \leq & {\left[\frac{M_{2}\left(G_{1}\right)+n_{2} M_{1}\left(G_{1}\right)+m_{1} n_{2}^{2}}{m_{1}}\right]^{m_{1}} \times\left[\frac{M_{2}\left(G_{2}\right)+n_{1} M_{1}\left(G_{2}\right)+m_{2} n_{1}^{2}}{m_{2}}\right]^{m_{2}} } \\
& \times\left[\frac{4 m_{1} m_{2}+2 n_{1} n_{2}\left(m_{1}+m_{2}\right)+\left(n_{1} n_{2}\right)^{2}}{n_{1} n_{2}}\right]^{n_{1} n_{2}}
\end{aligned}
$$

where $n_{1}$ and $n_{2}$ are the numbers of vertices of $G_{1}$ and $G_{2}$, and $m_{1}, m_{2}$ are the numbers of edges of $G_{1}$ and $G_{2}$, respectively. Moreover, the equality holds in (3) if and only if both $G_{1}$ and $G_{2}$ are regular graphs, that is, $G_{1} \vee G_{2}$ is a regular graph and the equality holds in (4) if and only if both $G_{1}$ and $G_{2}$ are regular graphs, that is, $G_{1} \vee G_{2}$ is a regular graph. 
Proof Now,

$$
\begin{aligned}
\prod_{1}\left(G_{1} \vee G_{2}\right) & =\prod_{\left(u_{i}, v_{j}\right) \in V\left(G_{1} \vee G_{2}\right)} d_{G_{1} \vee G_{2}}\left(u_{i}, v_{j}\right)^{2} \\
& =\prod_{u_{i} \in V\left(G_{1}\right)}\left(d_{G_{1}}\left(u_{i}\right)+n_{2}\right)^{2} \prod_{v_{j} \in V\left(G_{2}\right)}\left(d_{G_{2}}\left(v_{j}\right)+n_{1}\right)^{2} \\
& =\prod_{u_{i} \in V\left(G_{1}\right)}\left(d_{G_{1}}\left(u_{i}\right)^{2}+2 n_{2} d_{G_{1}}\left(u_{i}\right)+n_{2}^{2}\right) \prod_{v_{j} \in V\left(G_{2}\right)}\left(d_{G_{2}}\left(v_{j}\right)^{2}+2 n_{1} d_{G_{2}}\left(v_{j}\right)+n_{1}^{2}\right)
\end{aligned}
$$

and by (1) this above equality is actually less than or equal to

$$
\begin{aligned}
\leq & {\left[\frac{\sum_{u_{i} \in V\left(G_{1}\right)}\left(d_{G_{1}}\left(u_{i}\right)^{2}+2 n_{2} d_{G_{1}}\left(u_{i}\right)+n_{2}^{2}\right)}{n_{1}}\right]^{n_{1}} } \\
& \times\left[\sum_{v_{j} \in V\left(G_{2}\right)} \frac{\left(d_{G_{2}}\left(v_{j}\right)^{2}+2 n_{1} d_{G_{2}}\left(v_{j}\right)+n_{1}^{2}\right)}{n_{2}}\right]^{n_{2}} \\
= & {\left[\frac{M_{1}\left(G_{1}\right)+4 m_{1} n_{2}+n_{1} n_{2}^{2}}{n_{1}}\right]^{n_{1}} \times\left[\frac{M_{1}\left(G_{2}\right)+4 n_{1} m_{2}+n_{2} n_{1}^{2}}{n_{2}}\right]^{n_{2}} . }
\end{aligned}
$$

Moreover, the above equality holds if and only if

$$
d_{G_{1}}\left(u_{i}\right)^{2}+2 n_{2} d_{G_{1}}\left(u_{i}\right)+n_{2}^{2}=d_{G_{1}}\left(u_{k}\right)^{2}+2 n_{2} d_{G_{1}}\left(u_{k}\right)+n_{2}^{2} \quad\left(u_{i}, u_{k} \in V\left(G_{1}\right)\right)
$$

and

$$
d_{G_{2}}\left(v_{j}\right)^{2}+2 n_{1} d_{G_{2}}\left(v_{j}\right)+n_{1}^{2}=d_{G_{2}}\left(v_{\ell}\right)^{2}+2 n_{1} d_{G_{2}}\left(v_{\ell}\right)+n_{1}^{2} \quad\left(v_{j}, v_{\ell} \in V\left(G_{2}\right)\right)
$$

(by Lemma 1), that is, for $u_{i}, u_{k} \in V\left(G_{1}\right)$ and $v_{j}, v_{\ell} \in V\left(G_{2}\right)$,

$$
\left(d_{G_{1}}\left(u_{i}\right)-d_{G_{1}}\left(u_{k}\right)\right)\left(d_{G_{1}}\left(u_{i}\right)+d_{G_{1}}\left(u_{k}\right)+2 n_{2}\right)
$$

and

$$
\left(d_{G_{2}}\left(v_{j}\right)-d_{G_{2}}\left(v_{\ell}\right)\right)\left(d_{G_{2}}\left(v_{j}\right)+d_{G_{2}}\left(v_{\ell}\right)+2 n_{1}\right) .
$$

That is, for $u_{i}, u_{k} \in V\left(G_{1}\right)$ and $v_{j}, v_{\ell} \in V\left(G_{2}\right)$, we get $d_{G_{1}}\left(u_{i}\right)=d_{G_{1}}\left(u_{k}\right)$ and $d_{G_{2}}\left(v_{j}\right)=d_{G_{2}}\left(v_{\ell}\right)$. Hence the equality holds in (3) if and only if both $G_{1}$ and $G_{2}$ are regular graphs, that is, $G_{1} \vee G_{2}$ is a regular graph.

Now, since

$$
\prod_{2}\left(G_{1} \vee G_{2}\right)=\prod_{\left(u_{i}, v_{j}\right)\left(u_{k}, v_{\ell}\right) \in E\left(G_{1} \vee G_{2}\right)} d_{G_{1} \vee G_{2}}\left(u_{i}, v_{j}\right) d_{G_{1} \vee G_{2}}\left(u_{k}, v_{\ell}\right)
$$

we then obtain

$$
\begin{aligned}
= & \prod_{u_{i} u_{k} \in E\left(G_{1}\right)}\left(d_{G_{1}}\left(u_{i}\right)+n_{2}\right)\left(d_{G_{1}}\left(u_{k}\right)+n_{2}\right) \prod_{v_{j} v_{\ell} \in E\left(G_{2}\right)}\left(d_{G_{2}}\left(v_{j}\right)+n_{1}\right)\left(d_{G_{2}}\left(v_{\ell}\right)+n_{1}\right) \\
& \times \prod_{u_{i} \in V\left(G_{1}\right), v_{j} \in V\left(G_{2}\right)}\left(d_{G_{1}}\left(u_{i}\right)+n_{2}\right)\left(d_{G_{2}}\left(v_{j}\right)+n_{1}\right)
\end{aligned}
$$


and by (1)

$$
\begin{aligned}
\leq & {\left[\frac{\sum_{u_{i} u_{k} \in E\left(G_{1}\right)}\left(d_{G_{1}}\left(u_{i}\right) d_{G_{1}}\left(u_{k}\right)+n_{2}\left(d_{G_{1}}\left(u_{i}\right)+d_{G_{1}}\left(u_{k}\right)\right)+n_{2}^{2}\right)}{m_{1}}\right]^{m_{1}} } \\
& \times\left[\frac{\sum_{v_{j} v_{\ell} \in E\left(G_{2}\right)}\left(d_{G_{2}}\left(v_{j}\right) d_{G_{2}}\left(v_{\ell}\right)+n_{1}\left(d_{G_{2}}\left(v_{j}\right)+d_{G_{2}}\left(v_{\ell}\right)\right)+n_{1}^{2}\right)}{m_{2}}\right]^{m_{2}} \\
& \times\left[\frac{\sum_{u_{i} \in V\left(G_{1}\right), v_{j} \in V\left(G_{2}\right)}\left(d_{G_{1}}\left(u_{i}\right) d_{G_{2}}\left(v_{j}\right)+n_{2} d_{G_{2}}\left(v_{j}\right)+n_{1} d_{G_{1}}\left(u_{i}\right)+n_{1} n_{2}\right)}{n_{1} n_{2}}\right]^{n_{1} n_{2}} .
\end{aligned}
$$

However, from the last inequality, we get

$$
\begin{aligned}
= & {\left[\frac{M_{2}\left(G_{1}\right)+n_{2} M_{1}\left(G_{1}\right)+m_{1} n_{2}^{2}}{m_{1}}\right]^{m_{1}} \times\left[\frac{M_{2}\left(G_{2}\right)+n_{1} M_{1}\left(G_{2}\right)+m_{2} n_{1}^{2}}{m_{2}}\right]^{m_{2}} } \\
& \times\left[\frac{\sum_{u_{i} \in V\left(G_{1}\right)} d_{i} \sum_{v_{j} \in V\left(G_{2}\right)} d_{j}^{*}+n_{1} n_{2} \sum_{v_{i} \in V\left(G_{1}\right)} d_{i}+n_{1} n_{2} \sum_{v_{j} \in V\left(G_{2}\right)} d_{j}^{*}+n_{1}^{2} n_{2}^{2}}{n_{1} n_{2}}\right]^{n_{1} n_{2}} \\
= & {\left[\frac{M_{2}\left(G_{1}\right)+n_{2} M_{1}\left(G_{1}\right)+m_{1} n_{2}^{2}}{m_{1}}\right]^{m_{1}} \times\left[\frac{M_{2}\left(G_{2}\right)+n_{1} M_{1}\left(G_{2}\right)+m_{2} n_{1}^{2}}{m_{2}}\right]^{m_{2}} } \\
& \times\left[\frac{4 m_{1} m_{2}+2 n_{1} n_{2}\left(m_{1}+m_{2}\right)+\left(n_{1} n_{2}\right)^{2}}{n_{1} n_{2}}\right]^{n_{1} n_{2}} .
\end{aligned}
$$

Furthermore, for both connected graphs $G_{1}$ and $G_{2}$, the equality holds in (5) iff

$$
d_{G_{1}}\left(u_{i}\right) d_{G_{1}}\left(u_{r}\right)+n_{2}\left(d_{G_{1}}\left(u_{i}\right)+d_{G_{1}}\left(u_{r}\right)\right)+n_{2}^{2}=d_{G_{1}}\left(u_{i}\right) d_{G_{1}}\left(u_{k}\right)+n_{2}\left(d_{G_{1}}\left(u_{i}\right)+d_{G_{1}}\left(u_{k}\right)\right)+n_{2}^{2}
$$

for any $u_{i} u_{r}, u_{i} u_{k} \in E\left(G_{1}\right)$; and

$$
d_{G_{2}}\left(v_{j}\right) d_{G_{2}}\left(v_{r}\right)+n_{1}\left(d_{G_{2}}\left(v_{j}\right)+d_{G_{2}}\left(v_{r}\right)\right)+n_{1}^{2}=d_{G_{2}}\left(v_{j}\right) d_{G_{2}}\left(v_{\ell}\right)+n_{1}\left(d_{G_{2}}\left(v_{j}\right)+d_{G_{2}}\left(v_{\ell}\right)\right)+n_{1}^{2}
$$

for any $v_{j} v_{r}, v_{j} v_{\ell} \in E\left(G_{2}\right)$ as well as

$$
\begin{aligned}
& d_{G_{1}}\left(u_{i}\right) d_{G_{2}}\left(v_{j}\right)+n_{2} d_{G_{2}}\left(v_{j}\right)+n_{1} d_{G_{1}}\left(u_{i}\right)+n_{1} n_{2} \\
& =d_{G_{1}}\left(u_{i}\right) d_{G_{2}}\left(v_{\ell}\right)+n_{2} d_{G_{2}}\left(v_{\ell}\right)+n_{1} d_{G_{1}}\left(u_{i}\right)+n_{1} n_{2}
\end{aligned}
$$

for any $u_{i} \in V\left(G_{1}\right), v_{j}, v_{\ell} \in V\left(G_{2}\right)$; and

$$
\begin{aligned}
& d_{G_{1}}\left(u_{i}\right) d_{G_{2}}\left(v_{j}\right)+n_{2} d_{G_{2}}\left(v_{j}\right)+n_{1} d_{G_{1}}\left(u_{i}\right)+n_{1} n_{2} \\
& \quad=d_{G_{1}}\left(u_{k}\right) d_{G_{2}}\left(v_{j}\right)+n_{2} d_{G_{2}}\left(v_{j}\right)+n_{1} d_{G_{1}}\left(u_{k}\right)+n_{1} n_{2}
\end{aligned}
$$

for any $v_{j} \in V\left(G_{2}\right), u_{i}, u_{k} \in V\left(G_{1}\right)$ by Lemma 1 . Thus one can easily see that the equality holds in (5) if and only if for $u_{i}, u_{k} \in V\left(G_{1}\right)$ and $v_{j}, v_{\ell} \in V\left(G_{2}\right)$,

$$
d_{G_{1}}\left(u_{i}\right)=d_{G_{1}}\left(u_{k}\right) \text { and } \quad d_{G_{2}}\left(v_{j}\right)=d_{G_{2}}\left(v_{\ell}\right) .
$$

Hence the equality holds in (4) if and only if both $G_{1}$ and $G_{2}$ are regular graphs, that is, $G_{1} \vee G_{2}$ is a regular graph. 
Example 1 Consider two cycle graphs $C_{p}$ and $C_{q}$. We thus have

$$
\prod_{1}\left(C_{p} \vee C_{q}\right)=(p+2)^{2 q}(q+2)^{2 p} \quad \text { and } \quad \prod_{2}\left(C_{p} \vee C_{q}\right)=(p+2)^{(p+2) q}(q+2)^{(q+2) p} .
$$

The Cartesian product $G_{1} \otimes G_{2}$ of graphs $G_{1}$ and $G_{2}$ has the vertex set $V\left(G_{1} \times G_{2}\right)=$ $V\left(G_{1}\right) \times V\left(G_{2}\right)$ and $\left(u_{i}, v_{j}\right)\left(u_{k}, v_{\ell}\right)$ is an edge of $G_{1} \otimes G_{2}$ if

either $u_{i}=u_{k}$ and $v_{j} v_{\ell} \in E\left(G_{2}\right)$

or $u_{i} u_{k} \in E\left(G_{1}\right)$ and $v_{j}=v_{\ell}$.

Theorem 2 Let $G_{1}$ and $G_{2}$ be two connected graphs. Then

(i)

$$
\prod_{1}\left(G_{1} \otimes G_{2}\right) \leq\left[\frac{n_{2} M_{1}\left(G_{1}\right)+n_{1} M_{1}\left(G_{2}\right)+8 m_{1} m_{2}}{n_{1} n_{2}}\right]^{n_{1} n_{2}} .
$$

The equality holds in (6) if and only if $G_{1} \otimes G_{2}$ is a regular graph.

(ii)

$$
\begin{aligned}
\prod_{2}\left(G_{1} \otimes G_{2}\right) \leq & \frac{1}{\left(2 n_{1} m_{2}\right)^{2 n_{1} m_{2}}}\left(n_{1} M_{1}\left(G_{2}\right)+4 m_{1} m_{2}\right)^{2 n_{1} m_{2}} \\
& \times \frac{1}{\left(2 n_{2} m_{1}\right)^{2 n_{2} m_{1}}}\left(n_{2} M_{1}\left(G_{1}\right)+4 m_{1} m_{2}\right)^{2 n_{2} m_{1}} .
\end{aligned}
$$

Moreover, the equality holds in (7) if and only if $G_{1} \otimes G_{2}$ is a regular graph.

Proof By the definition of the first multiplicative Zagreb index, we have

$$
\begin{aligned}
\prod_{1}\left(G_{1} \otimes G_{2}\right) & =\prod_{\left(u_{i}, v_{j}\right) \in V\left(G_{1} \otimes G_{2}\right)}\left(d_{G_{1}}\left(u_{i}\right)+d_{G_{2}}\left(v_{j}\right)\right)^{2} \\
& =\prod_{u_{i} \in V\left(G_{1}\right)} \prod_{v_{j} \in V\left(G_{2}\right)}\left(d_{G_{1}}\left(u_{i}\right)+d_{G_{2}}\left(v_{j}\right)\right)^{2} .
\end{aligned}
$$

On the other hand, by (1)

$$
\leq\left[\frac{\sum_{u_{i} \in V\left(G_{1}\right)} \sum_{v_{j} \in V\left(G_{2}\right)}\left(d_{G_{1}}\left(u_{i}\right)^{2}+d_{G_{2}}\left(v_{j}\right)^{2}+2 d_{G_{1}}\left(u_{i}\right) d_{G_{2}}\left(v_{j}\right)\right)}{n_{1} n_{2}}\right]^{n_{1} n_{2}} .
$$

But as $\sum_{u_{i} \in V\left(G_{1}\right)} d_{G_{1}}\left(u_{i}\right)^{2}=M_{1}\left(G_{1}\right)$ and $\sum_{v_{j} \in V\left(G_{2}\right)} d_{G_{2}}\left(v_{j}\right)^{2}=M_{1}\left(G_{2}\right)$, the last statement in (8) is less than or equal to

$$
\leq\left[\frac{\sum_{u_{i} \in V\left(G_{1}\right)}\left(d_{G_{1}}\left(u_{i}\right)^{2} \sum_{v_{j} \in V\left(G_{2}\right)} 1+\sum_{v_{j} \in V\left(G_{2}\right)} d_{G_{2}}\left(v_{j}\right)^{2}+2 d_{G_{1}}\left(u_{i}\right) \sum_{v_{j} \in V\left(G_{2}\right)} d_{G_{2}}\left(v_{j}\right)\right)}{n_{1} n_{2}}\right]^{n_{1} n_{2}}
$$

which equals to

$$
\left[\frac{n_{2} M_{1}\left(G_{1}\right)+n_{1} M_{1}\left(G_{2}\right)+8 m_{1} m_{2}}{n_{1} n_{2}}\right]^{n_{1} n_{2}}
$$


Moreover, the equality holds in (8) if and only if $d_{G_{1}}\left(u_{i}\right)+d_{G_{2}}\left(v_{j}\right)=d_{G_{1}}\left(u_{k}\right)+d_{G_{2}}\left(v_{\ell}\right)$ for any $\left(u_{i}, v_{j}\right),\left(u_{k}, v_{\ell}\right) \in V\left(G_{1} \otimes G_{2}\right)$ by Lemma 1 . Since both $G_{1}$ and $G_{2}$ are connected graphs, one can easily see that the equality holds in (8) if and only if $d_{G_{1}}\left(u_{i}\right)=d_{G_{1}}\left(u_{k}\right)$, $u_{i}, u_{k} \in V\left(G_{1}\right)$ and $d_{G_{2}}\left(v_{j}\right)=d_{G_{2}}\left(v_{\ell}\right), v_{j}, v_{\ell} \in V\left(G_{2}\right)$. Hence the equality holds in (6) if and only if both $G_{1}$ and $G_{2}$ are regular graphs, that is, $G_{1} \otimes G_{2}$ is a regular graph. This completes the first part of the proof.

By the definition of the second multiplicative Zagreb index, we have

$$
\prod_{2}\left(G_{1} \otimes G_{2}\right)=\prod_{\left(u_{i}, v_{j}\right)\left(u_{k}, v_{\ell}\right) \in E\left(G_{1} \otimes G_{2}\right)}\left(d_{G_{1}}\left(u_{i}\right)+d_{G_{2}}\left(v_{j}\right)\right)\left(d_{G_{1}}\left(u_{k}\right)+d_{G_{2}}\left(v_{\ell}\right)\right) .
$$

This actually can be written as

$$
\begin{aligned}
\prod_{2}\left(G_{1} \otimes G_{2}\right)= & \prod_{u_{i} \in V\left(G_{1}\right)} \prod_{v_{j} v_{\ell} \in E\left(G_{2}\right)}\left(d_{G_{1}}\left(u_{i}\right)+d_{G_{2}}\left(v_{j}\right)\right)\left(d_{G_{1}}\left(u_{i}\right)+d_{G_{2}}\left(v_{\ell}\right)\right) \\
& \times \prod_{v_{j} \in V\left(G_{2}\right)} \prod_{u_{i} u_{k} \in E\left(G_{1}\right)}\left(d_{G_{1}}\left(u_{i}\right)+d_{G_{2}}\left(v_{j}\right)\right)\left(d_{G_{1}}\left(u_{k}\right)+d_{G_{2}}\left(v_{j}\right)\right)
\end{aligned}
$$

or, equivalently,

$$
\begin{aligned}
\prod_{2}\left(G_{1} \otimes G_{2}\right)= & \prod_{u_{i} \in V\left(G_{1}\right)} \prod_{v_{j} \in V\left(G_{2}\right)}\left(d_{G_{1}}\left(u_{i}\right)+d_{G_{2}}\left(v_{j}\right)\right)^{d_{G_{2}}\left(v_{j}\right)} \\
& \times \prod_{v_{j} \in V\left(G_{2}\right)} \prod_{u_{i} \in V\left(G_{1}\right)}\left(d_{G_{1}}\left(u_{i}\right)+d_{G_{2}}\left(v_{j}\right)\right)^{d_{G_{1}}\left(u_{i}\right)} .
\end{aligned}
$$

After that, by (2) we get

$$
\begin{aligned}
\prod_{2}\left(G_{1} \otimes G_{2}\right) \leq & \prod_{u_{i} \in V\left(G_{1}\right)}\left[\frac{\sum_{v_{j} \in V\left(G_{2}\right)} d_{G_{2}}\left(v_{j}\right)\left(d_{G_{1}}\left(u_{i}\right)+d_{G_{2}}\left(v_{j}\right)\right)}{2 m_{2}}\right]^{2 m_{2}} \\
& \times \prod_{v_{j} \in V\left(G_{2}\right)}\left[\frac{\sum_{u_{i} \in V\left(G_{1}\right)} d_{G_{1}}\left(u_{i}\right)\left(d_{G_{1}}\left(u_{i}\right)+d_{G_{2}}\left(v_{j}\right)\right)}{2 m_{1}}\right]^{2 m_{1}} .
\end{aligned}
$$

Moreover, since

$$
\begin{aligned}
& \sum_{u_{i} \in V\left(G_{1}\right)} d_{G_{1}}\left(u_{i}\right)=2 m_{1}, \quad \sum_{v_{j} \in V\left(G_{2}\right)} d_{G_{2}}\left(v_{j}\right)=2 m_{2} \quad \text { and } \\
& \sum_{u_{i} \in V\left(G_{1}\right)} d_{G_{1}}\left(u_{i}\right)^{2}=M_{1}\left(G_{1}\right), \quad \sum_{v_{j} \in V\left(G_{2}\right)} d_{G_{2}}\left(v_{j}\right)^{2}=M_{1}\left(G_{2}\right) .
\end{aligned}
$$

By (1) the final statement in (9) becomes

$$
\begin{aligned}
& =\prod_{u_{i} \in V\left(G_{1}\right)}\left[\frac{M_{1}\left(G_{2}\right)+2 m_{2} d_{G_{1}}\left(u_{i}\right)}{2 m_{2}}\right]^{2 m_{2}} \times \prod_{v_{j} \in V\left(G_{2}\right)}\left[\frac{M_{1}\left(G_{1}\right)+2 m_{1} d_{G_{2}}\left(v_{j}\right)}{2 m_{1}}\right]^{2 m_{1}} \\
& \leq \frac{1}{\left(2 m_{2}\right)^{2 n_{1} m_{2}}}\left[\frac{\sum_{u_{i} \in V\left(G_{1}\right)}\left(M_{1}\left(G_{2}\right)+2 m_{2} d_{G_{1}}\left(u_{i}\right)\right)}{n_{1}}\right]^{2 n_{1} m_{2}}
\end{aligned}
$$




$$
\begin{aligned}
& \times \frac{1}{\left(2 m_{1}\right)^{2 n_{2} m_{1}}}\left[\frac{\sum_{v_{j} \in V\left(G_{2}\right)}\left(M_{1}\left(G_{1}\right)+2 m_{1} d_{G_{2}}\left(v_{j}\right)\right)}{n_{2}}\right]^{2 n_{2} m_{1}} \\
= & \frac{1}{\left(2 n_{1} m_{2}\right)^{2 n_{1} m_{2}}}\left(n_{1} M_{1}\left(G_{2}\right)+4 m_{1} m_{2}\right)^{2 n_{1} m_{2}} \\
& \times \frac{1}{\left(2 n_{2} m_{1}\right)^{2 n_{2} m_{1}}}\left(n_{2} M_{1}\left(G_{1}\right)+4 m_{1} m_{2}\right)^{2 n_{2} m_{1}} .
\end{aligned}
$$

Hence the second part of the proof is over.

The equality holds in (9) and (10) if and only if $d_{G_{2}}\left(v_{j}\right)=d_{G_{2}}\left(v_{\ell}\right)$ for any $v_{j}, v_{\ell} \in V\left(G_{2}\right)$ and $d_{G_{1}}\left(u_{i}\right)=d_{G_{1}}\left(u_{k}\right)$ for any $u_{i}, u_{k} \in V\left(G_{1}\right)$ by Lemmas 1 and 2 . Hence the equality holds in (7) if and only if both $G_{1}$ and $G_{2}$ are regular graphs, that is, $G_{1} \otimes G_{2}$ is a regular graph. This completes the proof.

Example 2 Consider a cycle graph $C_{p}$ and a complete graph $K_{q}$. We thus have

$$
\prod_{1}\left(C_{p} \otimes K_{q}\right)=(q+1)^{2 p q} \quad \text { and } \quad \prod_{2}\left(C_{p} \otimes K_{q}\right)=(q+1)^{(q+1) p q}
$$

The corona product $G_{1} \circ G_{2}$ of two graphs $G_{1}$ and $G_{2}$ is defined to be the graph $\Gamma$ obtained by taking one copy of $G_{1}$ (which has $n_{1}$ vertices) and $n_{1}$ copies of $G_{2}$, and then joining the $i$ th vertex of $G_{1}$ to every vertex in the $i$ th copy of $G_{2}, i=1,2, \ldots, n_{1}$.

Let $G_{1}=(V, E)$ and $G_{2}=(V, E)$ be two graphs such that $V\left(G_{1}\right)=\left\{u_{1}, u_{2}, \ldots, u_{n_{1}}\right\}$, $\left|E\left(G_{1}\right)\right|=m_{1}$ and $V\left(G_{2}\right)=\left\{v_{1}, v_{2}, \ldots, v_{n_{2}}\right\},\left|E\left(G_{2}\right)\right|=m_{2}$. Then it follows from the definition of the corona product that $G_{1} \circ G_{2}$ has $n_{1}\left(1+n_{2}\right)$ vertices and $m_{1}+n_{1} m_{2}+n_{1} n_{2}$ edges, where $V\left(G_{1} \circ G_{2}\right)=\left\{\left(u_{i}, v_{j}\right), i=1,2, \ldots, n_{1} ; j=0,1,2, \ldots, n_{2}\right\}$ and $E\left(G_{1} \circ G_{2}\right)=$ $\left\{\left(\left(u_{i}, v_{0}\right),\left(u_{k}, v_{0}\right)\right),\left(u_{i}, u_{k}\right) \in E\left(G_{1}\right)\right\} \cup\left\{\left(\left(u_{i}, v_{j}\right),\left(u_{i}, v_{\ell}\right)\right),\left(v_{j}, v_{\ell}\right) \in E\left(G_{2}\right), i=1,2, \ldots, n_{1}\right\} \cup$ $\left\{\left(\left(u_{i}, v_{0}\right),\left(u_{i}, v_{\ell}\right)\right), \ell=1,2, \ldots, n_{2}, i=1,2, \ldots, n_{1}\right\}$. It is clear that if $G_{1}$ is connected, then $G_{1} \circ G_{2}$ is connected, and in general $G_{1} \circ G_{2}$ is not isomorphic to $G_{2} \circ G_{1}$.

Theorem 3 The first and second multiplicative Zagreb indices of the corona product are computed as follows:

(i)

$$
\prod_{1}\left(G_{1} \circ G_{2}\right) \leq \frac{1}{n_{1}^{n_{1}} n_{2}^{n_{1} n_{2}}} M_{1}\left(G_{1}\right)^{n_{1}}\left(M_{1}\left(G_{2}\right)+4 m_{2}+n_{2}\right)^{n_{1} n_{2}}
$$

(ii)

$$
\begin{aligned}
\prod_{2}\left(G_{1} \circ G_{2}\right) \leq & {\left[\frac{M_{2}\left(G_{1}\right)+n_{2} M_{1}\left(G_{1}\right)+n_{2}^{2}}{m_{1}}\right]^{m_{1}}\left[\frac{M_{2}\left(G_{2}\right)+M_{1}\left(G_{2}\right)+1}{m_{2}}\right]^{n_{1} m_{2}} } \\
& \times\left[\frac{4 m_{1} m_{2}+n_{1} n_{2}^{2}+2 m_{1} n_{2}+2 m_{2} n_{1} n_{2}}{n_{1} n_{2}}\right]^{n_{1} n_{2}}
\end{aligned}
$$

where $M_{1}\left(G_{i}\right)$ and $M_{2}\left(G_{i}\right)$ are the first and second Zagreb indices of $G_{i}$, where $i=1,2$, respectively. Moreover, both equalities in (11) and (12) hold if and only if $G_{1} \circ G_{2}$ is a regular graph. 
Proof By the definition of the first multiplicative Zagreb index, we have

$$
\begin{aligned}
\prod_{1}\left(G_{1} \circ G_{2}\right)= & \prod_{\left(u_{i}, v_{j}\right) \in V\left(G_{1} \circ G_{2}\right)} d_{G_{1} \circ G_{2}}\left(u_{i}, v_{j}\right)^{2} \\
= & \prod_{u_{i} \in V\left(G_{1}\right)}\left(d_{G_{1}}\left(u_{i}\right)+n_{2}\right)^{2} \prod_{u_{i} \in V\left(G_{1}\right)} \prod_{v_{j} \in V\left(G_{2}\right)}\left(d_{G_{2}}\left(v_{j}\right)+1\right)^{2} \\
= & \prod_{u_{i} \in V\left(G_{1}\right)}\left(d_{G_{1}}\left(u_{i}\right)^{2}+2 n_{2} d_{G_{1}}\left(u_{i}\right)+n_{2}^{2}\right) \\
& \times\left[\prod_{v_{j} \in V\left(G_{2}\right)}\left(d_{G_{2}}\left(v_{j}\right)^{2}+2 d_{G_{2}}\left(v_{j}\right)+1\right)^{2}\right]^{n_{1}} \\
\leq & {\left[\frac{\sum_{u_{i} \in V\left(G_{1}\right)}\left(d_{G_{1}}\left(u_{i}\right)^{2}+2 n_{2} d_{G_{1}}\left(u_{i}\right)+n_{2}^{2}\right)}{n_{1}}\right]^{n_{1}} } \\
& \times\left[\frac{\sum_{v_{j} \in V\left(G_{2}\right)}\left(d_{G_{2}}\left(v_{j}\right)^{2}+2 d_{G_{2}}\left(v_{j}\right)+1\right)}{n_{2}}\right]^{n_{1} n_{2}} \text { by }(1) \\
= & \frac{1}{n_{1}^{n_{1}} n_{2}^{n_{1} n_{2}}}\left(M_{1}\left(G_{1}\right)+4 n_{2} m_{1}+n_{1} n_{2}^{2}\right)^{n_{1}}\left(M_{1}\left(G_{2}\right)+4 m_{2}+n_{2}\right)^{n_{1} n_{2}} .
\end{aligned}
$$

The equality holds in (13) if and only if $d_{G_{1}}\left(u_{i}\right)=d_{G_{1}}\left(u_{k}\right), u_{i}, u_{k} \in V\left(G_{1}\right)$ and $d_{G_{2}}\left(v_{j}\right)=$ $d_{G_{2}}\left(v_{\ell}\right), v_{j}, v_{\ell} \in V\left(G_{2}\right)$, that is, both $G_{1}$ and $G_{2}$ are regular graphs, that is, $G_{1} \circ G_{2}$ is a regular graph.

By the definition of the second multiplicative Zagreb index, we have

$$
\begin{aligned}
\prod_{2}\left(G_{1} \circ G_{2}\right)= & \prod_{\left(u_{i}, v_{j}\right)\left(u_{k}, v_{\ell}\right) \in E\left(G_{1} \circ G_{2}\right)} d_{G_{1} \circ G_{2}}\left(u_{i}, v_{j}\right) d_{G_{1} \circ G_{2}}\left(u_{k}, v_{\ell}\right) \\
= & \prod_{u_{i} u_{k} \in E\left(G_{1}\right)}\left(d_{G_{1}}\left(u_{i}\right)+n_{2}\right)\left(d_{G_{1}}\left(u_{k}\right)+n_{2}\right) \\
& \times \prod_{u_{i} \in V\left(G_{1}\right)} \prod_{v_{j} \in V\left(G_{2}\right)}\left(d_{G_{1}}\left(u_{i}\right)+n_{2}\right)\left(d_{G_{2}}\left(v_{j}\right)+1\right) \\
& \times \prod_{u_{i} \in V\left(G_{1}\right)} \prod_{v_{j} v_{\ell} \in E\left(G_{2}\right)}\left(d_{G_{2}}\left(v_{j}\right)+1\right)\left(d_{G_{2}}\left(v_{\ell}\right)+1\right) \\
= & \prod_{u_{i} u_{k} \in E\left(G_{1}\right)}\left(d_{G_{1}}\left(u_{i}\right) d_{G_{1}}\left(u_{k}\right)+n_{2}\left(d_{G_{1}}\left(u_{i}\right)+d_{G_{1}}\left(u_{k}\right)\right)+n_{2}^{2}\right) \\
& \times\left[\prod_{u_{i} \in V\left(G_{1}\right)}\left(d_{G_{1}}\left(u_{i}\right)+n_{2}\right)\right]^{n_{2}}\left[\prod_{v_{j} \in V\left(G_{2}\right)}\left(d_{G_{1}}\left(v_{j}\right)+1\right)\right]^{n_{1}} \\
& \times\left[\prod_{v_{j} v_{\ell} \in E\left(G_{2}\right)}\left(d_{G_{2}}\left(v_{j}\right) d_{G_{2}}\left(v_{\ell}\right)+\left(d_{G_{2}}\left(v_{j}\right)+d_{G_{2}}\left(v_{\ell}\right)\right)+1\right)\right]^{n_{1}} \\
\leq & {\left[\frac{M_{2}\left(G_{1}\right)+n_{2} M_{1}\left(G_{1}\right)+n_{2}^{2} m_{1}}{m_{1}}\right]^{m_{1}} \times\left[\frac{2 m_{1}+n_{1} n_{2}}{n_{1}}\right]^{n_{1} n_{2}} } \\
& \times\left[\frac{2 m_{2}+n_{2}}{n_{2}}\right]^{n_{1} n_{2}} \times\left[\frac{M_{2}\left(G_{2}\right)+M_{1}\left(G_{2}\right)+m_{2}}{m_{2}}\right]^{n_{1} m_{2}} \text { by }(1) .
\end{aligned}
$$


The above equality holds if and only if $d_{G_{1}}\left(u_{i}\right)=d_{G_{1}}\left(u_{k}\right)$ for any $u_{i}, u_{k} \in V\left(G_{1}\right)$ and $d_{G_{2}}\left(v_{j}\right)=$ $d_{G_{2}}\left(v_{\ell}\right)$ for any $v_{j}, v_{\ell} \in V\left(G_{2}\right)$, that is, both $G_{1}$ and $G_{2}$ are regular graphs, which implies that $G_{1} \circ G_{2}$ is a regular graph. This completes the proof.

Example $3 \prod_{1}\left(C_{p} \circ K_{q}\right)=q^{2 p q}(q+2)^{2 p}$ and $\prod_{2}\left(C_{p} \circ K_{q}\right)=q^{p q^{2}}(q+2)^{p(q+2)}$.

The composition (also called lexicographic product [12]) $G=G_{1}\left[G_{2}\right]$ of graphs $G_{1}$ and $G_{2}$ with disjoint vertex sets $V\left(G_{1}\right)$ and $V\left(G_{2}\right)$ and edge sets $E\left(G_{1}\right)$ and $E\left(G_{2}\right)$ is the graph with a vertex set $V\left(G_{1}\right) \times V\left(G_{2}\right)$ and $\left(u_{i}, v_{j}\right)$ is adjacent to $\left(u_{k}, v_{\ell}\right)$ whenever

either $u_{i}$ is adjacent to $u_{k}$,

or $u_{i}=u_{k}$ and $v_{j}$ is adjacent to $v_{\ell}$.

Theorem 4 The first and second multiplicative Zagreb indices of the composition $G_{1}\left[G_{2}\right]$ of graphs $G_{1}$ and $G_{2}$ are bounded above as follows:

(i)

$$
\prod_{1}\left(G_{1}\left[G_{2}\right]\right) \leq \frac{1}{\left(n_{1} n_{2}\right)^{n_{1} n_{2}}}\left[n_{2}^{3} M_{1}\left(G_{1}\right)+8 n_{2} m_{1} m_{2}+n_{1} M_{1}\left(G_{2}\right)\right]^{n_{1} n_{2}},
$$

(ii)

$$
\begin{aligned}
\prod_{2}\left(G_{1}\left[G_{2}\right]\right) \leq & \frac{1}{\left(n_{1} m_{2}\right)^{n_{1} m_{2}}}\left[m_{2} n_{2}^{2} M_{1}\left(G_{1}\right)+2 n_{2} m_{1} M_{1}\left(G_{2}\right)+n_{1} M_{2}\left(G_{2}\right)\right]^{n_{1} m_{2}} \\
& \times \frac{1}{\left(n_{2} m_{1}\right)^{m_{1} n_{2}^{2}}}\left[n_{2}^{3} M_{2}\left(G_{1}\right)+m_{1} M_{1}\left(G_{2}\right)+2 m_{2} n_{2} M_{1}\left(G_{1}\right)\right]^{n_{2}^{2} m_{1}},
\end{aligned}
$$

where $M_{1}\left(G_{i}\right)$ and $M_{2}\left(G_{i}\right)$ are the first and second Zagreb indices of $G_{i}$, where $i=1,2$. Moreover, the equalities in (14) and (15) hold if and only if $G_{1} \circ G_{2}$ is a regular graph.

Proof By the definition of the first multiplicative Zagreb index, we have

$$
\begin{aligned}
& \prod_{1}\left(G_{1}\left[G_{2}\right]\right) \\
& \quad=\prod_{\left(u_{i}, v_{j}\right) \in V\left(G_{1}\left[G_{2}\right]\right)} d_{G_{1}\left[G_{2}\right]}\left(u_{i}, v_{j}\right)^{2} \\
& \quad=\prod_{u_{i} \in V\left(G_{1}\right)} \prod_{v_{j} \in V\left(G_{2}\right)}\left(d_{G_{1}}\left(u_{i}\right) n_{2}+d_{G_{2}}\left(v_{j}\right)\right)^{2} \\
& \leq\left[\frac{\sum_{u_{i} \in V\left(G_{1}\right)} \sum_{v_{j} \in V\left(G_{2}\right)}\left(n_{2}^{2} d_{G_{1}}\left(u_{i}\right)^{2}+2 n_{2} d_{G_{1}}\left(u_{i}\right) d_{G_{2}}\left(v_{j}\right)+d_{G_{2}}\left(v_{j}\right)^{2}\right)}{n_{1} n_{2}}\right]^{n_{1} n_{2}} \\
& \quad=\frac{1}{\left(n_{1} n_{2}\right)^{n_{1} n_{2}}}\left[n_{2}^{3} M_{1}\left(G_{1}\right)+8 n_{2} m_{1} m_{2}+n_{1} M_{1}\left(G_{2}\right)\right]^{n_{1} n_{2}} .
\end{aligned}
$$

The equality holds in (16) if and only if $d_{G_{1}}\left(u_{i}\right)=d_{G_{1}}\left(u_{k}\right), u_{i}, u_{k} \in V\left(G_{1}\right)$ and $d_{G_{2}}\left(v_{j}\right)=$ $d_{G_{2}}\left(v_{\ell}\right), v_{j}, v_{\ell} \in V\left(G_{2}\right)$ (by Lemma 1), that is, both $G_{1}$ and $G_{2}$ are regular graphs, that is, $G_{1} \circ G_{2}$ is a regular graph. 
By the definition of the second multiplicative Zagreb index, we have

$$
\begin{aligned}
\prod_{2} & \left(G_{1}\left[G_{2}\right]\right) \\
= & \prod_{\left(u_{i}, v_{j}\right)\left(u_{k}, v_{\ell}\right) \in E\left(G_{1}\left[G_{2}\right]\right)} d_{G_{1} \circ G_{2}}\left(u_{i}, v_{j}\right) d_{G_{1}\left[G_{2}\right]}\left(u_{k}, v_{\ell}\right) \\
= & \prod_{u_{i} \in V\left(G_{1}\right)} \prod_{v_{j} v_{\ell} \in E\left(G_{2}\right)}\left(d_{G_{1}}\left(u_{i}\right) n_{2}+d_{G_{2}}\left(v_{j}\right)\right)\left(d_{G_{1}}\left(u_{i}\right) n_{2}+d_{G_{2}}\left(v_{\ell}\right)\right) \\
& \times \prod_{u_{i} u_{k} \in E\left(G_{1}\right)} \prod_{v_{j} \in V\left(G_{2}\right)}\left[\left(d_{G_{1}}\left(u_{i}\right) n_{2}+d_{G_{2}}\left(v_{j}\right)\right)\left(d_{G_{1}}\left(u_{k}\right) n_{2}+d_{G_{2}}\left(v_{j}\right)\right)\right]^{n_{2}} \\
\leq & \prod_{u_{i} \in V\left(G_{1}\right)}\left[\frac{m_{2} n_{2}^{2} d_{G_{1}}\left(u_{i}\right)^{2}+n_{2} d_{G_{1}}\left(u_{i}\right) M_{1}\left(G_{2}\right)+M_{2}\left(G_{2}\right)}{m_{2}}\right]^{m_{2}} \\
& \times \prod_{u_{i} u_{k} \in E\left(G_{1}\right)}\left[\frac{n_{2}^{3} d_{G_{1}}\left(u_{i}\right) d_{G_{1}}\left(u_{k}\right)+M_{1}\left(G_{2}\right)+2 m_{2} n_{2}\left(d_{G_{1}}\left(u_{i}\right)+d_{G_{1}}\left(u_{k}\right)\right)}{n_{2}}\right]^{n_{2}^{2}} \\
\leq & \frac{1}{m_{2}^{n_{1} m_{2}}}\left[\frac{m_{2} n_{2}^{2} M_{1}\left(G_{1}\right)+2 n_{2} m_{1} M_{1}\left(G_{2}\right)+n_{1} M_{2}\left(G_{2}\right)}{n_{1}}\right]^{n_{1} m_{2}} \\
& \times \frac{1}{\left(n_{2}\right)^{m_{1} n_{2}^{2}}}\left[\frac{n_{2}^{3} M_{2}\left(G_{1}\right)+m_{1} M_{1}\left(G_{2}\right)+2 m_{2} n_{2} M_{1}\left(G_{1}\right)}{m_{1}}\right]^{n_{2}^{2} m_{1}},
\end{aligned}
$$

which gives the required result in (15).

The equality holds in (17) and (18) if and only if $d_{G_{1}}\left(u_{i}\right)=d_{G_{1}}\left(u_{k}\right), u_{i}, u_{k} \in V\left(G_{1}\right)$ and $d_{G_{2}}\left(v_{j}\right)=d_{G_{2}}\left(v_{\ell}\right), v_{j}, v_{\ell} \in V\left(G_{2}\right)$ (by Lemma 1 ), that is, both $G_{1}$ and $G_{2}$ are regular graphs, that is, $G_{1} \circ G_{2}$ is a regular graph.

Example $4 \prod_{1}\left(C_{p}\left[C_{q}\right]\right)=2^{2 p q}(q+1)^{2 p q}$ and $\prod_{2}\left(C_{p}\left[C_{q}\right]\right)=2^{2 p q(q+1)}(q+1)^{2 p q(q+1)}$.

The disjunction $G_{1} \otimes G_{2}$ of graphs $G_{1}$ and $G_{2}$ is the graph with a vertex set $V\left(G_{1}\right) \times V\left(G_{2}\right)$ and $\left(u_{i}, v_{j}\right)$ is adjacent to $\left(u_{k}, v_{\ell}\right)$ whenever $u_{i} u_{k} \in E\left(G_{1}\right)$ or $v_{j} v_{\ell} \in E\left(G_{2}\right)$.

Theorem 5 The first and second multiplicative Zagreb indices of the disjunction are computed as follows:

(i)

$$
\begin{aligned}
\prod_{1}\left(G_{1} \otimes G_{2}\right) \leq & \frac{1}{\left(n_{1} n_{2}\right)^{n_{1} n_{2}}}\left[n_{2}^{3} M_{1}\left(G_{1}\right)+n_{1}^{3} M_{1}\left(G_{2}\right)+M_{1}\left(G_{1}\right) M_{1}\left(G_{2}\right)\right. \\
& \left.+8 n_{1} n_{2} m_{1} m_{2}-4 n_{1} m_{1} M_{1}\left(G_{2}\right)-4 n_{2} m_{2} M_{1}\left(G_{1}\right)\right]^{n_{1} n_{2}},
\end{aligned}
$$

(ii)

$$
\begin{aligned}
& \prod_{2}\left(G_{1} \otimes G_{2}\right) \\
& \quad \leq\left[\frac{M_{1}\left(G_{1}\right)\left(n_{2}^{3}+M_{1}\left(G_{2}\right)-4 n_{2} m_{2}\right)+M_{1}\left(G_{2}\right)\left(n_{1}^{2}-4 n_{1} m_{1}\right)+8 n_{1} n_{2} m_{1} m_{2}}{Q}\right]^{Q},
\end{aligned}
$$


where $Q=\sum_{u_{i} \in V\left(G_{1}\right)} \sum_{v_{j} \in V\left(G_{2}\right)} P=2\left(n_{2}^{2} m_{1}+n_{1}^{2} m_{2}-2 m_{1} m_{2}\right)$ and $M_{1}\left(G_{i}\right)$ is the first Zagreb index of $G_{i}, i=1,2$. Moreover, the equalities in (19) and (20) hold if and only if $G_{1} \circ G_{2}$ is a regular graph.

Proof We have $d_{G_{1} \otimes G_{2}}\left(u_{i}, v_{j}\right)=n_{2} d_{G_{1}}\left(u_{i}\right)+n_{1} d_{G_{2}}\left(v_{j}\right)-d_{G_{1}}\left(u_{i}\right) d_{G_{2}}\left(v_{j}\right)$. By the definition of the first multiplicative Zagreb index, we have

$$
\begin{aligned}
\prod_{1} & \left(G_{1} \otimes G_{2}\right) \\
= & \prod_{\left(u_{i}, v_{j}\right) \in V\left(G_{1} \otimes G_{2}\right)} d_{G_{1} \otimes G_{2}}\left(u_{i}, v_{j}\right)^{2} \\
= & \prod_{u_{i} \in V\left(G_{1}\right)} \prod_{v_{j} \in V\left(G_{2}\right)}\left(n_{2} d_{G_{1}}\left(u_{i}\right)+n_{1} d_{G_{2}}\left(v_{j}\right)-d_{G_{1}}\left(u_{i}\right) d_{G_{2}}\left(v_{j}\right)\right)^{2} \\
\leq & {\left[\frac{\sum_{u_{i} \in V\left(G_{1}\right)} \sum_{v_{j} \in V\left(G_{2}\right)}\left(n_{2} d_{G_{1}}\left(u_{i}\right)+n_{1} d_{G_{2}}\left(v_{j}\right)-d_{G_{1}}\left(u_{i}\right) d_{G_{2}}\left(v_{j}\right)\right)^{2}}{n_{1} n_{2}}\right]^{n_{1} n_{2}} } \\
= & \frac{1}{\left(n_{1} n_{2}\right)^{n_{1} n_{2}}}\left[n_{2}^{3} M_{1}\left(G_{1}\right)+n_{1}^{3} M_{1}\left(G_{2}\right)+M_{1}\left(G_{1}\right) M_{1}\left(G_{2}\right)\right. \\
& \left.+8 n_{1} n_{2} m_{1} m_{2}-4 n_{1} m_{1} M_{1}\left(G_{2}\right)-4 n_{2} m_{2} M_{1}\left(G_{1}\right)\right]^{n_{1} n_{2}} .
\end{aligned}
$$

The equality holds in (21) if and only if $d_{G_{1}}\left(u_{i}\right)=d_{G_{1}}\left(u_{k}\right), u_{i}, u_{k} \in V\left(G_{1}\right)$ and $d_{G_{2}}\left(v_{j}\right)=$ $d_{G_{2}}\left(v_{\ell}\right), v_{j}, v_{\ell} \in V\left(G_{2}\right)$ (by Lemma 1 ), that is, both $G_{1}$ and $G_{2}$ are regular graphs, that is, $G_{1} \circ G_{2}$ is a regular graph.

By the definition of the second multiplicative Zagreb index, we have

$$
\begin{aligned}
\prod_{2}\left(G_{1} \otimes G_{2}\right) & =\prod_{\left(u_{i}, v_{j}\right)\left(u_{k}, v_{\ell}\right) \in E\left(G_{1} \otimes G_{2}\right)} d_{G_{1} \otimes G_{2}}\left(u_{i}, v_{j}\right) d_{G_{1} \otimes G_{2}}\left(u_{k}, v_{\ell}\right) \\
& =\prod_{u_{i} \in V\left(G_{1}\right)} \prod_{v_{j} \in V\left(G_{2}\right)} P^{P}
\end{aligned}
$$

where

$$
P=n_{2} d_{G_{1}}\left(u_{i}\right)+n_{1} d_{G_{2}}\left(v_{j}\right)-d_{G_{1}}\left(u_{i}\right) d_{G_{2}}\left(v_{j}\right) .
$$

Using the weighted arithmetic-geometric mean inequality in $(2), \prod_{2}\left(G_{1} \otimes G_{2}\right)$ is less than or equal to

$$
\begin{aligned}
& \leq\left[\frac{\sum_{u_{i} \in V\left(G_{1}\right)} \sum_{v_{j} \in V\left(G_{2}\right)}\left(n_{2} d_{G_{1}}\left(u_{i}\right)+n_{1} d_{G_{2}}\left(v_{j}\right)-d_{G_{1}}\left(u_{i}\right) d_{G_{2}}\left(v_{j}\right)\right)^{2}}{\sum_{u_{i} \in V\left(G_{1}\right)} \sum_{v_{j} \in V\left(G_{2}\right)} P}\right]^{\sum_{u_{i} \in V\left(G_{1}\right)} \sum_{v_{j} \in V\left(G_{2}\right)} P} \\
& =\left[\frac{M_{1}\left(G_{1}\right)\left(n_{2}^{3}+M_{1}\left(G_{2}\right)-4 n_{2} m_{2}\right)+M_{1}\left(G_{2}\right)\left(n_{1}^{2}-4 n_{1} m_{1}\right)+8 n_{1} n_{2} m_{1} m_{2}}{Q}\right]^{Q},
\end{aligned}
$$

where

$$
Q=\sum_{u_{i} \in V\left(G_{1}\right)} \sum_{v_{j} \in V\left(G_{2}\right)} P=2\left(n_{2}^{2} m_{1}+n_{1}^{2} m_{2}-2 m_{1} m_{2}\right) .
$$

Hence the first part of the proof is over. 
The equality holds in (22) if and only if $d_{G_{1}}\left(u_{i}\right)=d_{G_{1}}\left(u_{k}\right)$, where $u_{i}, u_{k} \in V\left(G_{1}\right)$ and $d_{G_{2}}\left(v_{j}\right)=d_{G_{2}}\left(v_{\ell}\right)$, where $v_{j}, v_{\ell} \in V\left(G_{2}\right)$ (by Lemma 1 ), that is, both $G_{1}$ and $G_{2}$ are regular graphs, and so the graph $G_{1} \circ G_{2}$ is regular.

Example $5 \prod_{1}\left(K_{p} \otimes C_{q}\right)=(p q-q+2)^{2 p q}$ and $\prod_{2}\left(K_{p} \otimes C_{q}\right)=(p q-q+2)^{p q(p q-q+2)}$.

The symmetric difference $G_{1} \oplus G_{2}$ of two graphs $G_{1}$ and $G_{2}$ is the graph with a vertex set $V\left(G_{1}\right) \times V\left(G_{2}\right)$ in which $\left(u_{i}, v_{j}\right)$ is adjacent to $\left(u_{k}, v_{\ell}\right)$ whenever $u_{i}$ is adjacent to $u_{k}$ in $G_{1}$ or $v_{i}$ is adjacent to $v_{\ell}$ in $G_{2}$, but not both. The degree of a vertex $\left(u_{i}, v_{j}\right)$ of $G_{1} \oplus G_{2}$ is given by

$$
d_{G_{1} \oplus G_{2}}\left(u_{i}, v_{j}\right)=n_{2} d_{G_{1}}\left(u_{i}\right)+n_{1} d_{G_{2}}\left(v_{j}\right)-2 d_{G_{1}}\left(u_{i}\right) d_{G_{2}}\left(v_{j}\right),
$$

while the number of edges in $G_{1} \oplus G_{2}$ is $n_{1}^{2} m_{2}+n_{2}^{2} m_{1}-4 m_{1} m_{2}$.

Theorem 6 The first and second multiplicative Zagreb indices of the symmetric difference $G_{1} \oplus G_{2}$ of two graphs $G_{1}$ and $G_{2}$ are bounded above as follows:

(i)

$$
\begin{aligned}
\prod_{1}\left(G_{1} \oplus G_{2}\right) \leq & \frac{1}{\left(n_{1} n_{2}\right)^{n_{1} n_{2}}}\left[n_{2}^{3} M_{1}\left(G_{1}\right)+n_{1}^{3} M_{1}\left(G_{2}\right)+4 M_{1}\left(G_{1}\right) M_{1}\left(G_{2}\right)\right. \\
& \left.+8 n_{1} n_{2} m_{1} m_{2}-8 n_{1} m_{1} M_{1}\left(G_{2}\right)-8 n_{2} m_{2} M_{1}\left(G_{1}\right)\right]^{n_{1} n_{2}}
\end{aligned}
$$

(ii)

$$
\begin{aligned}
& \prod_{2}\left(G_{1} \oplus G_{2}\right) \\
& \quad \leq\left[\frac{M_{1}\left(G_{1}\right)\left(n_{2}^{3}+4 M_{1}\left(G_{2}\right)-8 n_{2} m_{2}\right)+M_{1}\left(G_{2}\right)\left(n_{1}^{3}-8 n_{1} m_{1}\right)+8 n_{1} n_{2} m_{1} m_{2}}{Q}\right]^{Q},
\end{aligned}
$$

where $Q=\sum_{u_{i} \in V\left(G_{1}\right)} \sum_{v_{j} \in V\left(G_{2}\right)} P=2\left(n_{2}^{2} m_{1}+n_{1}^{2} m_{2}-4 m_{1} m_{2}\right)$ and $M_{1}\left(G_{i}\right)$ is the first Zagreb index of $G_{i}$, for $i=1,2$. Moreover, the equalities in (23) and (24) hold if and only if $G_{1} \circ G_{2}$ is a regular graph.

Proof We have

$$
d_{G_{1} \oplus G_{2}}\left(u_{i}, v_{j}\right)=n_{2} d_{G_{1}}\left(u_{i}\right)+n_{1} d_{G_{2}}\left(v_{j}\right)-2 d_{G_{1}}\left(u_{i}\right) d_{G_{2}}\left(v_{j}\right) .
$$

By the definition of the first multiplicative Zagreb index, we have

$$
\begin{aligned}
& \prod_{1}\left(G_{1} \oplus G_{2}\right) \\
& =\prod_{\left(u_{i}, v_{j}\right) \in V\left(G_{1} \oplus G_{2}\right)} d_{G_{1} \otimes G_{2}}\left(u_{i}, v_{j}\right)^{2} \\
& =\prod_{u_{i} \in V\left(G_{1}\right)} \prod_{v_{j} \in V\left(G_{2}\right)}\left(n_{2} d_{G_{1}}\left(u_{i}\right)+n_{1} d_{G_{2}}\left(v_{j}\right)-2 d_{G_{1}}\left(u_{i}\right) d_{G_{2}}\left(v_{j}\right)\right)^{2}
\end{aligned}
$$




$$
\begin{aligned}
\leq & {\left[\frac{\sum_{u_{i} \in V\left(G_{1}\right)} \sum_{v_{j} \in V\left(G_{2}\right)}\left(n_{2} d_{G_{1}}\left(u_{i}\right)+n_{1} d_{G_{2}}\left(v_{j}\right)-2 d_{G_{1}}\left(u_{i}\right) d_{G_{2}}\left(v_{j}\right)\right)^{2}}{n_{1} n_{2}}\right]^{n_{1} n_{2}} } \\
= & \frac{1}{\left(n_{1} n_{2}\right)^{n_{1} n_{2}}}\left[n_{2}^{3} M_{1}\left(G_{1}\right)+n_{1}^{3} M_{1}\left(G_{2}\right)+4 M_{1}\left(G_{1}\right) M_{1}\left(G_{2}\right)+8 n_{1} n_{2} m_{1} m_{2}\right. \\
& \left.-8 n_{1} m_{1} M_{1}\left(G_{2}\right)-8 n_{2} m_{2} M_{1}\left(G_{1}\right)\right]^{n_{1} n_{2}} .
\end{aligned}
$$

The equality holds in (25) if and only if $d_{G_{1}}\left(u_{i}\right)=d_{G_{1}}\left(u_{k}\right), u_{i}, u_{k} \in V\left(G_{1}\right)$ and $d_{G_{2}}\left(v_{j}\right)=$ $d_{G_{2}}\left(v_{\ell}\right), v_{j}, v_{\ell} \in V\left(G_{2}\right)$ (by Lemma 1 ), that is, both $G_{1}$ and $G_{2}$ are regular graphs, which implies that $G_{1} \circ G_{2}$ is a regular graph.

By the definition of the second multiplicative Zagreb index, we have

$$
\begin{aligned}
\prod_{2}\left(G_{1} \oplus G_{2}\right) & =\prod_{\left(u_{i}, v_{j}\right)\left(u_{k}, v_{\ell}\right) \in E\left(G_{1} \otimes G_{2}\right)} d_{G_{1} \otimes G_{2}}\left(u_{i}, v_{j}\right) d_{G_{1} \otimes G_{2}}\left(u_{k}, v_{\ell}\right) \\
& =\prod_{u_{i} \in V\left(G_{1}\right)} \prod_{v_{j} \in V\left(G_{2}\right)} P^{P}
\end{aligned}
$$

where $P=n_{2} d_{G_{1}}\left(u_{i}\right)+n_{1} d_{G_{2}}\left(v_{j}\right)-2 d_{G_{1}}\left(u_{i}\right) d_{G_{2}}\left(v_{j}\right)$.

Using the weighted arithmetic-geometric mean inequality in (2), we get

$$
\begin{aligned}
& \prod_{u_{i} \in V\left(G_{1}\right)} \prod_{v_{j} \in V\left(G_{2}\right)} P^{P} \\
& \leq\left[\frac{\sum_{u_{i} \in V\left(G_{1}\right)} \sum_{v_{j} \in V\left(G_{2}\right)}\left(n_{2} d_{G_{1}}\left(u_{i}\right)+n_{1} d_{G_{2}}\left(v_{j}\right)-2 d_{G_{1}}\left(u_{i}\right) d_{G_{2}}\left(v_{j}\right)\right)^{2}}{\sum_{u_{i} \in V\left(G_{1}\right)} \sum_{v_{j} \in V\left(G_{2}\right)} P}\right]^{\sum_{u_{i} \in V\left(G_{1}\right)} \sum_{v_{j} \in V\left(G_{2}\right)} P} \\
& =\left[\frac{M_{1}\left(G_{1}\right)\left(n_{2}^{3}+4 M_{1}\left(G_{2}\right)-8 n_{2} m_{2}\right)+M_{1}\left(G_{2}\right)\left(n_{1}^{3}-8 n_{1} m_{1}\right)+8 n_{1} n_{2} m_{1} m_{2}}{Q}\right]^{Q},
\end{aligned}
$$

where $Q=\sum_{u_{i} \in V\left(G_{1}\right)} \sum_{v_{j} \in V\left(G_{2}\right)} P=2\left(n_{2}^{2} m_{1}+n_{1}^{2} m_{2}-4 m_{1} m_{2}\right)$. First part of the proof is over.

The equality holds in (26) if and only if $d_{G_{1}}\left(u_{i}\right)=d_{G_{1}}\left(u_{k}\right), u_{i}, u_{k} \in V\left(G_{1}\right)$ and $d_{G_{2}}\left(v_{j}\right)=$ $d_{G_{2}}\left(v_{\ell}\right), v_{j}, v_{\ell} \in V\left(G_{2}\right)$ (by Lemma 1 ), that is, both $G_{1}$ and $G_{2}$ are regular graphs, which implies that $G_{1} \circ G_{2}$ is a regular graph.

Example $6 \prod_{1}\left(G_{1} \oplus G_{2}\right)=(p+q-2)^{2 p q}$ and $\prod_{2}\left(G_{1} \oplus G_{2}\right)=(p+q-2)^{p q(p+q-2)}$.

Competing interests

The authors declare that they have no competing interests.

Authors' contributions

All authors completed the paper together. All authors read and approved the final manuscript.

\section{Author details}

'Department of Mathematics, Sungkyunkwan University, Suwon, 440-746, Republic of Korea. ${ }^{2}$ Department of Mathematics, Faculty of Arts and Science, Uludağ University, Gorukle Campus, Bursa, 16059, Turkey. ${ }^{3}$ Department of Mathematics, Faculty of Science, Selçuk University, Campus, Konya, 42075, Turkey.

\section{Acknowledgements}

Dedicated to Professor Hari M Srivastava.

All authors except the first one are partially supported by Research Project Offices of Uludağ (2012-15 and 2012-19) and Selçuk Universities. K.C. Das thanks for support the Sungkyunkwan University BK21 Project, BK21 Math Modeling HRD Div.

Sungkyunkwan University, Suwon, Republic of Korea.

Received: 19 December 2012 Accepted: 15 February 2013 Published: 5 March 2013 


\section{References}

1. Todeschini, R, Ballabio, D, Consonni, V: Novel molecular descriptors based on functions of new vertex degrees. In: Gutman, I, Furtula, B (eds.) Novel Molecular Structure Descriptors - Theory and Applications I, pp. 73-100. Univ. Kragujevac, Kragujevac (2010)

2. Todeschini, R, Consonni, V: New local vertex invariants and molecular descriptors based on functions of the vertex degrees. MATCH Commun. Math. Comput. Chem. 64, 359-372 (2010)

3. Eliasi, M, Iranmanesh, A, Gutman, I: Multiplicative versions of first Zagreb index. MATCH Commun. Math. Comput. Chem. 68, 217-230 (2012)

4. Gutman, I: Multiplicative Zagreb indices of trees. Bull. Soc. Math. Banja Luka 18, 17-23 (2011)

5. Liu, J, Zhang, Q: Sharp upper bounds on multiplicative Zagreb indices. MATCH Commun. Math. Comput. Chem. 68 231-240 (2012)

6. Xu, K, Hua, H: A unified approach to extremal multiplicative Zagreb indices for trees, unicyclic and bicyclic graphs. MATCH Commun. Math. Comput. Chem. 68, 241-256 (2012)

7. Xu, K, Das, KC: Trees, unicyclic and bicyclic graphs extremal with respect to multiplicative sum Zagreb index. MATCH Commun. Math. Comput. Chem. 68(1), 257-272 (2012)

8. Bondy, JA, Murty, USR: Graph Theory with Applications. Macmillan Co., New York (1976)

9. Khalifeh, MH, Azari, HY, Ashrafi, AR: The hyper-Wiener index of graph operations. Comput. Math. Appl. 56, 1402-1407 (2008)

10. Khalifeh, MH, Azari, HY, Ashrafi, AR: The first and second Zagreb indices on of some graph operations. Discrete Appl. Math. 157, 804-811 (2009)

11. Imrich, W, Klavžar, S: Product Graphs: Structure and Recognition. Wiley, New York (2000)

12. Harary, F: Graph Theory, p. 22. Addison-Wesley, Reading (1994)

\section{Submit your manuscript to a SpringerOpen ${ }^{\circ}$ journal and benefit from:}

- Convenient online submission

- Rigorous peer review

- Immediate publication on acceptance

Open access: articles freely available online

- High visibility within the field

- Retaining the copyright to your article 